\title{
Evaluation of Parameters Affecting Magnetic Abrasive Finishing on Concave Freeform Surface of Al Alloy via RSM Method
}

\author{
Mehrdad Vahdati and SeyedAlireza Rasouli \\ Department of Mechanical Engineering, K. N. Toosi University of Technology, Tehran 19395-1999, Iran \\ Correspondence should be addressed to SeyedAlireza Rasouli; sarasouli@mail.kntu.ac.ir
}

Received 29 February 2016; Accepted 28 June 2016

Academic Editor: Donato Sorgente

Copyright ( 2016 M. Vahdati and S. Rasouli. This is an open access article distributed under the Creative Commons Attribution License, which permits unrestricted use, distribution, and reproduction in any medium, provided the original work is properly cited.

\begin{abstract}
The attempts of researchers in industries to obtain accurate and high quality surfaces led to the invention of new methods of finishing. Magnetic abrasive finishing (MAF) is a relatively new type of finishing in which the magnetic field is used to control the abrasive tools. Applications such as the surface of molds are ones of the parts which require very high surface smoothness. Usually this type of parts has freeform surface. In this study, the effect of magnetic abrasive process parameters on freeform surfaces of parts made of aluminum is examined. This method is obtained through combination of magnetic abrasive process and Control Numerical Computer (CNC). The use of simple hemisphere for installation on the flat area of the magnets as well as magnets' spark in curve form is a measure done during testing the experiments. The design of experiments is based on response surface methodology. The gap, the rotational speed of the spindle, and the feed rate are found influential and regression equations governing the process are also determined. The impact of intensity of the magnetic field is obtained using the finite element software of Maxwell. Results show that in concave areas of the surface, generally speaking, the surface roughness decreases to $0.2 \mu \mathrm{m}$ from its initial $1.3 \mu \mathrm{m}$ roughness. However, in some points the lowest surface roughness of $0.08 \mu \mathrm{m}$ was measured.
\end{abstract}

\section{Introduction}

Finishing is among latest processes which are performed on the workpiece. This process considerably influences the performance and lifetime of the product. There is a direct relation between the machining accuracy, surface roughness, and lifespan of the produced parts. The increasing growth of the automation in industries and increase in numerical control machines and robots lead to the achievement of high accurate surfaces with very fine surface roughness [1]. In some branches of products, like molds, surface roughness determines the lifespan. Furthermore, surface quality of molds remarkably influences the quality of the produced parts. Usually, molds possess three directional intricate freeform surfaces. Generally finishing freeform surfaces faces limitations. Currently, this process is done mostly manually which relies on the expertise of the worker which is far behind the development of the new modern manufacturing process. This hand-performed task is not practically feasible and it is very sensitive to human factors. Thus, material removal and surface roughness are hardly similar in molds or similar components with intricate curves and surfaces [2].

On the other hand, one of finishing processes developed in recent years is magnetic abrasive finishing (MAF). Flexible magnetic abrasive brush can easily deform due to magnetic field strength and match itself to the shape of the surface. The advantage is that the tool is not rigid and there is no dressing; otherwise, it would be necessary to manufacture different tools for different surfaces. Size of abrasive particles is some microns and this lets the abrasive brush reach any complicated surface and nonachievable region [3]. Self-sharpening, high adoptability, negligible increase in temperature during finishing in comparison with other finishing processes, suitable control on imposing force on particles, causing very little residual stress on the surface of the workpiece, and avoiding initiation of the microcracks are some of MAF advantages which increase its application [4]. In Figure 1 a schematic of MAF process can be seen [5]. Moreover, in case of its application in mold manufacturing, recast layers caused by electro-discharge machining process provide suitable space 


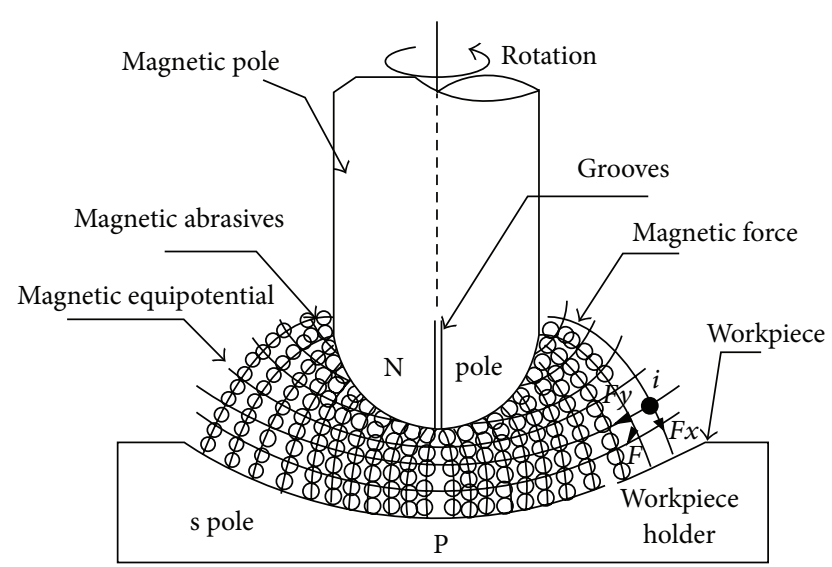

Figure 1: Schematic of MAF process.

for microcrack initiation; this method can simply remove these layers from the surface [6]. Also, considering lower normal force on abrasive particles (around or less than some $\mu \mathrm{Ns}$ ) penetration depth of the abrasive particles is about $1 \mu \mathrm{m}$ and less and therefore this finishing process does not change geometrical and dimensional tolerances of the workpiece.

Combining Computer Numerical Control, CNC, system and MAF, the shape of the brush can match with the intricate $3 \mathrm{D}$ curves and finishing of the complicated freeform surfaces of the molds becomes possible. Therefore, with an automatic control of the process parameters a very smooth surface with fine uniform surface roughness can be achieved.

In most reported researches and in industrial practices MAF has been performed on parts with plane surfaces and internal/external cylinders [7]. Lin et al., using Taguchi method, studied parameters like rotational speed of spindle, feed speed, amount of lubricant, gap, and amount of abrasive powder on the surface of a stainless steel 304 workpiece with low curvature. They could decrease surface roughness value from $0.158 \mu \mathrm{m}$ to $0.102 \mu \mathrm{m}$ [8]. They found out that amount of abrasive particles, feed speed, and finishing gap are significant parameters on surface roughness. Gap was the most effective one and its optimum amount was in the range of 1 to $2 \mathrm{~mm}$. Yin and Shinmura investigated the effect of vibration on the finishing process of the surface with low curvature [9]. Workpiece in horizontal and vertical and combined orientations was vibrated in high amplitudes and low frequencies and its influence was investigated on magnetic field, finishing pressure on abrasive particles, and process performance. Vibration in vertical and horizontal directions had the highest influence in reducing of the surface roughness. Y. J. Kim et al. introduced a novel method in finishing of the molds surface. In this new technique there is no need for CNC and instead, using guiding wheels passing the curved path with constant gap, magnetic abrasive finishing is performed. It should be mentioned that applied workpieces have concave and convex curvature with low slope. Zhang et al. in 2009 analyzed the theory of NURB curves on freeform surfaces and investigated their effects on MAF process [10]. Ding et al. considered time and its effect on surface roughness reduction of the concave and convex surfaces [11]. Anzai et al. studied the MAF on spark machined mold surfaces and they could considerably reduce the thickness of the recast layer [12].

Reviewing the reported researches one can say that MAF on mold freeform surfaces with high slope has never been modeled. To investigate significant factors on reduction average surface roughness, modeling and optimization of MAF are performed using Response Surface Method. In order to estimate the force on abrasive particles by magnetic field strength, PHVWE Teslameter in the range of 0-2 Tesla is used to measure and also Maxwell finite element software is employed to simulate magnetic flux density.

In this study design and manufacturing of tools, measuring and simulation, design and manufacture of workpiece, design of experiments, selection of suitable parameters, modeling, and simulation of MAF are discussed.

\section{Experimental Setup}

2.1. Tool. MAF required magnetic field is produced using an electrical or permanent magnet. Producing a variable magnetic field and possibility of easy separation of magnetic particles from the magnet surface are among this electrical magnet's advantages. To create an electromagnet generally many turns of wire are closely spaced and consequently they form a magnetic field. The central part of an electromagnet is a magnetic core created from a ferromagnetic material such as iron and this core is covered with many turns of wire which is usually made of copper. The magnetic core is the main part making a magnetic flux and with higher concentrations there will be a more powerful magnet [13].

Equation (1) can be used to calculate the density of magnetic flux in the center of solenoid:

$$
B=K \mu_{0} n I
$$

where $I$ is the electric current and $n$ is the number of solenoids per unit of length which is calculated using (2) and $\mu_{0}$ is relative magnetic permeability in vacuum $(\mathrm{Wb} /(\mathrm{A}-\mathrm{m}))$ :

$$
n=\frac{N}{L}
$$

where $N$ is the total number of solenoids and $L$ is the length of the wire. Moreover, $K$ is the coefficient of relative magnetic permeability of the core.

The use of materials with high relative magnetic permeability in the core of solenoid can have a significant impact in creating higher magnetic flux density. Usually, materials such as pure iron, nickel, and cobalt are used for this purpose.

However, when the radius of the solenoid is small in comparison with its length and its rings are very close together, the magnetic field inside the solenoid will be uniform at the points far from the edges. In such a condition, the impact of radius of the core could be neglected.

To obtain the desired magnetic flux density it is possible to use the following ways: increasing the number of wire turns per unit of length of wire and increasing the electric current. Usually copper wires with small diameter $(1 \mathrm{~mm})$ are used to create a solenoid. As a result, because of the high length and small diameter of the wires, the wire resistance 
will be increased. Therefore, when using a fixed voltage, it is not possible to increase the flow rate too much. On the other hand, with increasing the diameter of copper wire used, the volume of the magnet will increase. The increase in the number of turns of wire not only increases the amount of heat due to the loss of electricity but also increases the size of electric magnets.

The following section presents information and details about some electrical magnets which have been used in the MAF process.

Singh et al. used an electrical magnet for MAF process. They used a magnet with a diameter of $77 \mathrm{~mm}$ and height of $55 \mathrm{~mm}$. A copper wire turn was used to create magnetic field. In addition, to achieve a higher concentration of field lines and to create magnets, an iron core with a diameter of 38 was used. Using a power supply of $0-25$ volts and an electric current of 0-1 amperes, a magnetic field of 0-0.44 Tesla was created [14]. Moreover, the magnet used in the research laboratory at Baghdad University had the following characteristics [15]:

The material of the iron core: $\mathrm{C} 15$ low carbon steel.

The cross section of the iron core: $A=14 \mathrm{~cm}$.

The length of the iron core: $L=75 \mathrm{~mm}$.

The diameter of the copper wire of the magnetic coil: $\varnothing=1 \mathrm{~mm}$.

The number of turns: $N=2400$.

A round flat faced electromagnet with a diameter of $100 \mathrm{~mm}$ and height of $57 \mathrm{~mm}$ was used for experimentation in Chandigarh Engineering College by Gill [16]. Taking into consideration the dimensions of the magnets used, it is clear that electrical magnets occupy too much space. Moreover, as in MAF on straight and freeform surfaces, the magnet rotates and wire cannot be used to send electrical energy to the coil. To overcome this problem slip ring with graphite is used. To cool down the coils during operation a cooling system is required. Considering all aforementioned problems regarding application of electrical magnets, for its lower volume, easy mounting, and lower price a permanent magnet is applied in this study.

In MAF process on straight surfaces due to rotation of the tool, cylindrical magnets are used to produce magnetic fields. It is clear that in finishing of freeform surfaces magnets with surface straight cannot be applied due to the curvature of the surfaces because finishing path's required constant gap between magnet and workpiece surface will lead to collision between magnet and the surface. In this process, similar to finishing of freeform surfaces, ball nose tools should be used. Spherical heads of these tools move on the intricate surfaces without collision. Based on slip curvature, diameter of these tools commonly is up to $20 \mathrm{~mm}$. In MAF the head of the magnet should be formed in the shape of a hemisphere. Two ways can be followed to do this; first hemispherical iron head can be connected to the magnet. Figure 2 shows hemispherical iron heads and magnet fixture.

In order to facilitate the movement of the magnetic field, materials with higher relative magnetic permeability should

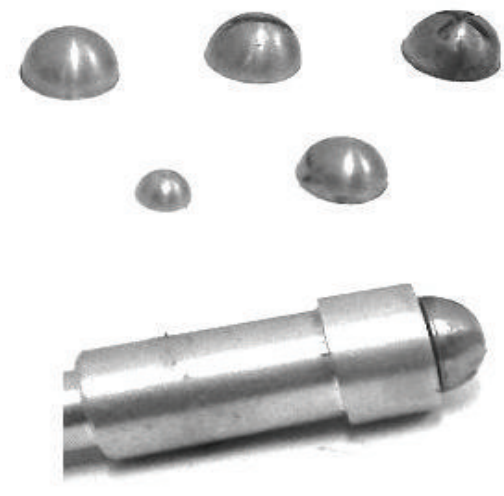

Figure 2: Hemispheres made of $99.8 \%$ pure iron.

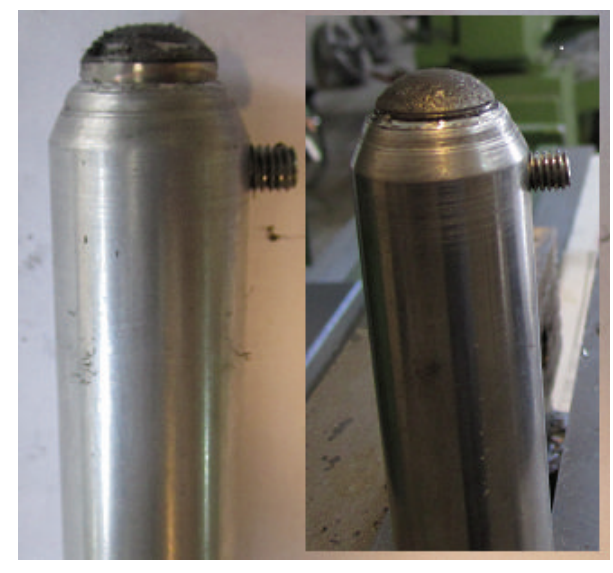

FIGURE 3: Spark machined magnet with its fixture.

be used. In materials with high relative magnetic permeability, pure iron (99.8\%) is more easily approachable. To identify the passing magnetic flux density both measurements and simulations are followed.

In simulations, iron hemisphere with radius of $8 \mathrm{~mm}$ is connected to a cylindrical magnet with diameter of 16 and height of $20 \mathrm{~mm}$. It should be noted that the relative magnetic permeability of the iron changes with variation of the magnetic field strength. Here, as intensity of the magnetic field produced by the magnet is much higher than 400 (A per M), the relative magnetic permeability is close to 2400. Creating curvature on the surface of the magnet is the second possible way which is followed here. Machining and electro-discharge machining can be used to manufacture a magnet with hemispherical shape. Due to brittle nature of sintered $\mathrm{NdFeB}$ commercial magnet with trade code N35, mechanical machining faces problems and does not provide a uniform surface. EDM can produce a better surface. Figure 3 shows spark machined magnet with its fixture. $2 \mathrm{D}$ and $3 \mathrm{D}$ simulation models are illustrated in Figure 4.

Figures 5 and 6 can be used to compare the effect of either iron hemisphere or hemispherical magnet on magnetic flux 

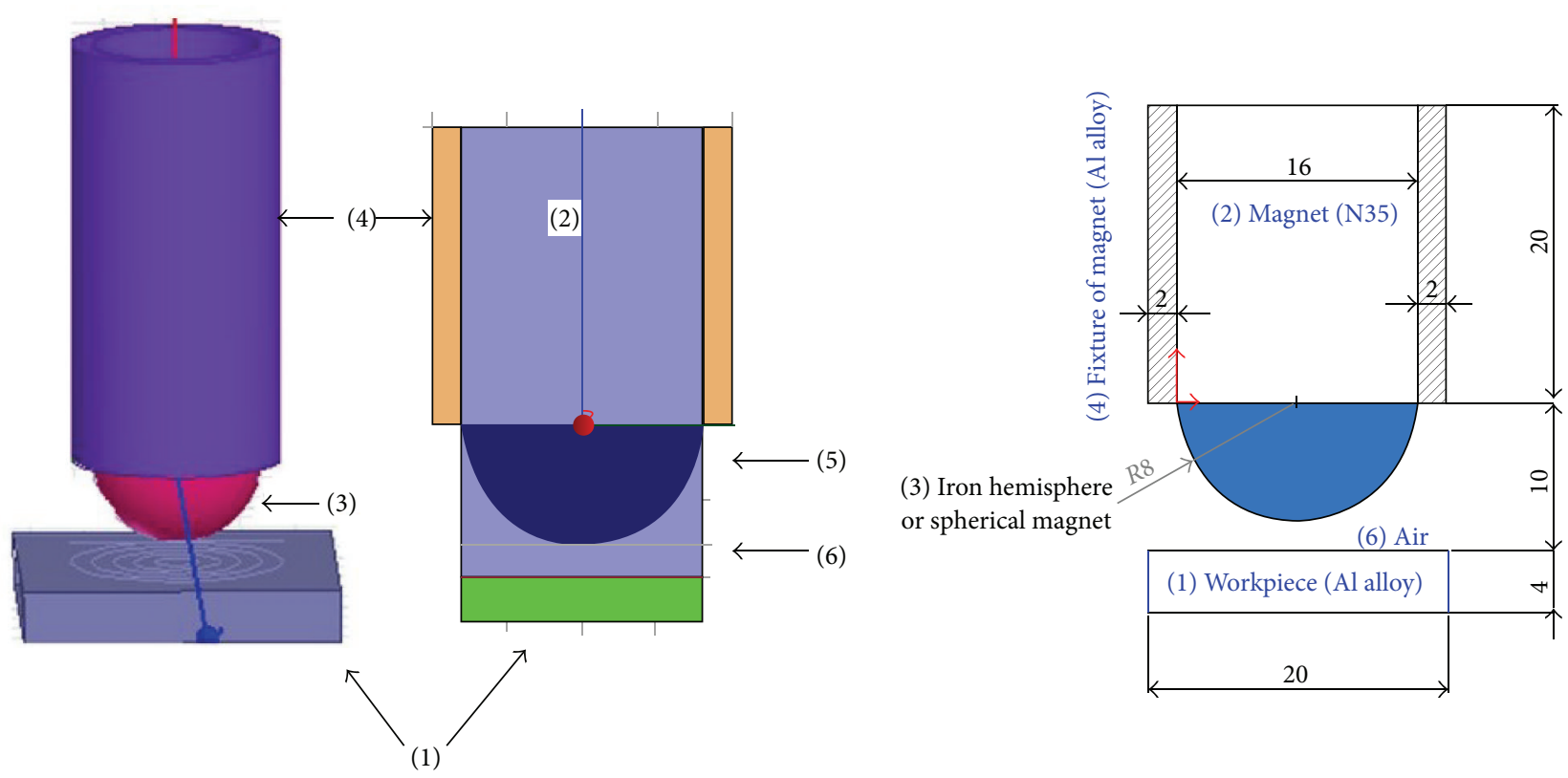

Figure 4: 2D and 3D simulation models: (1) workpiece $(20 \times 20 \times 5 \mathrm{~mm} \mathrm{Al}$ alloy), (2) magnet $(\varnothing 16 \times 20 \mathrm{~mm} \mathrm{~N} 35)$, (3) spherical magnet (Ø16 mm), (4) magnet fixture (Ø22 $\varnothing 16 \times 20 \mathrm{~mm}$ Al alloy), (5) iron hemisphere (Ø16 mm), and (6) air (thickness between iron hemisphere and workpiece $=2 \mathrm{~mm})$.

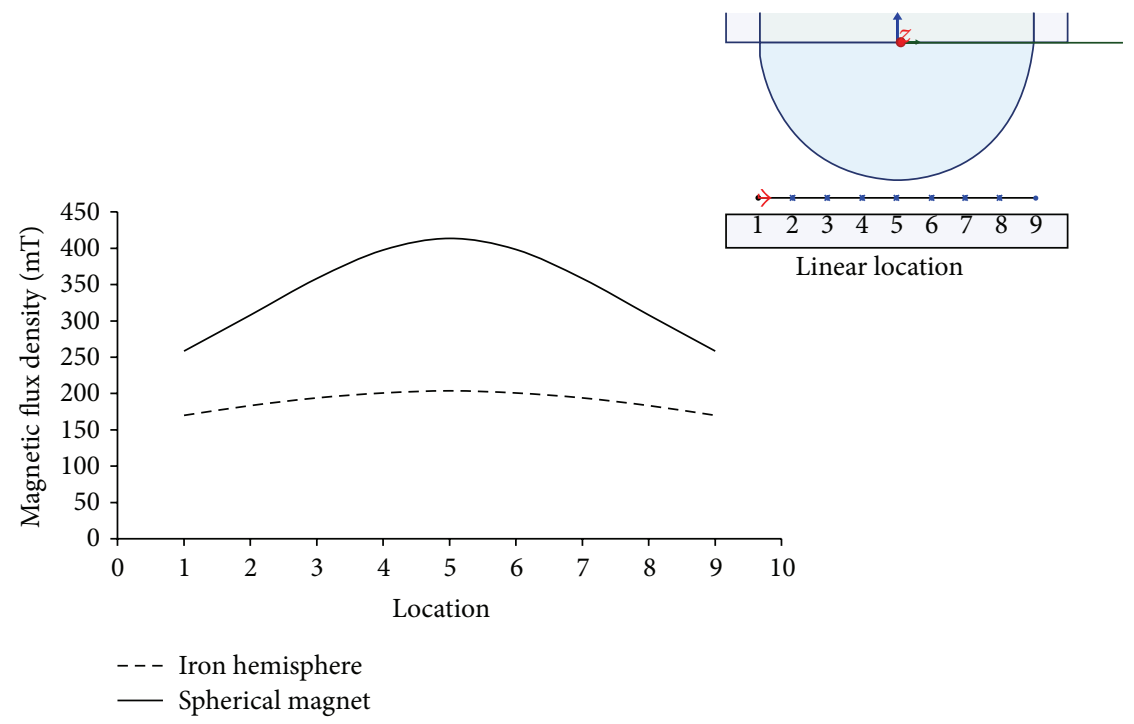

FIGURE 5: Magnetic flux density distribution at $2 \mathrm{~mm}$ distance from the surface in linear direction based on simulation results.

density based on simulation results. Magnetic flux density is measured at $2 \mathrm{~mm}$ distance from the external surface of the hemisphere circular and linear directions (Figure 5). It should be mentioned that workpiece which is located in front of hemisphere is made of non-ferromagnetic aluminum.

To verify simulation results, measurements are performed using calibrated Teslameter at $2 \mathrm{~mm}$ distance from the surface. Measuring method, equipment, and results are illustrated in Figures 7 and 8. All equipment applied for measuring magnetic flux density is made of non-ferromagnetic aluminum. Measurement path as it was for simulation was both circular and linear. Comparing Figures 6 and 8 it can be derived that measurements correlate well with simulation results. Average density of magnetic flux is presented in Table 1 for both simulation and measurements. Figure 9 depicts how that abrasive powder locates around the hemispherical magnet. Considering both simulation and experiment it can be concluded that the magnetic flux density around the hemispherical magnet is higher than that around the iron hemisphere. This fact causes better and more uniform distribution of the abrasive powder around the hemispherical magnet. In high velocities, iron hemisphere 


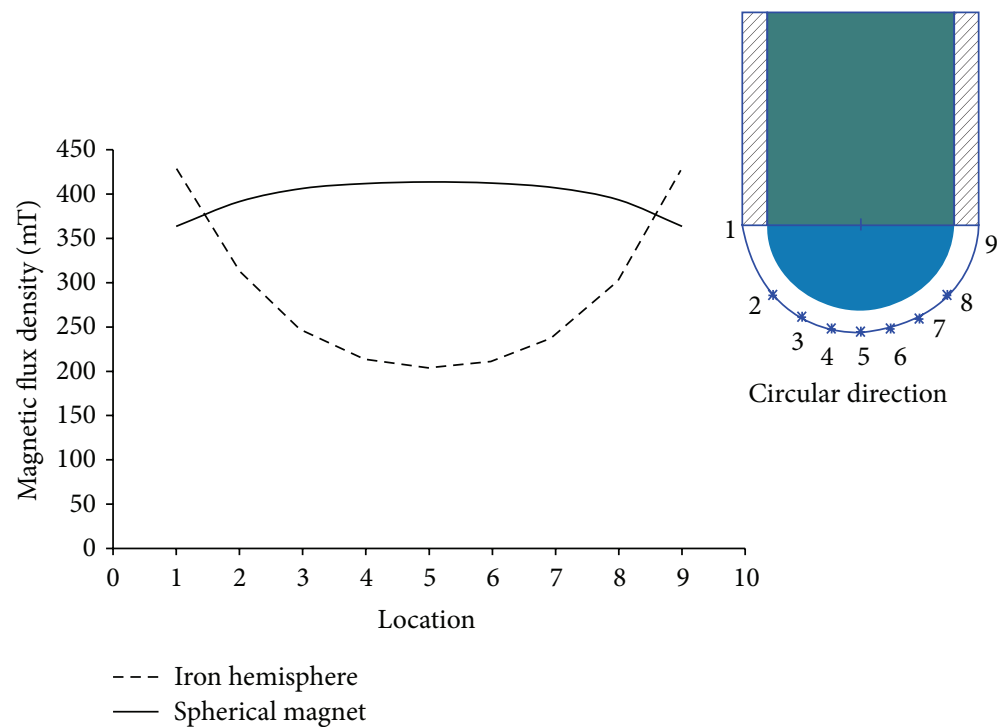

FIgURE 6: Magnetic flux density distribution at $2 \mathrm{~mm}$ distance from the surface in circular direction based on simulation results.

TABLE 1: Average measured and simulated magnetic flux density (mT).

\begin{tabular}{lccccc}
\hline & $\begin{array}{c}\text { Linear distance } \\
2 \mathrm{~mm} \\
\text { (simulation) }\end{array}$ & $\begin{array}{c}\text { Linear distance } \\
2 \mathrm{~mm} \\
\text { (measurement) }\end{array}$ & $\begin{array}{c}\text { Difference } \\
(\%)\end{array}$ & $\begin{array}{c}\text { Circular } \\
\text { distance } \\
2 \mathrm{~mm} \\
\text { (simulation) }\end{array}$ & $\begin{array}{c}\text { Circular distance } \\
2 \mathrm{~mm} \\
\text { (measurement) }\end{array}$ \\
\hline Iron hemisphere & 0.185 & 0.148 & $25 \%$ & 0.266 & 0.217 \\
Spherical magnet & 0.32 & 0.26 & $23 \%$ & 0.42 & 0.363 \\
\hline
\end{tabular}

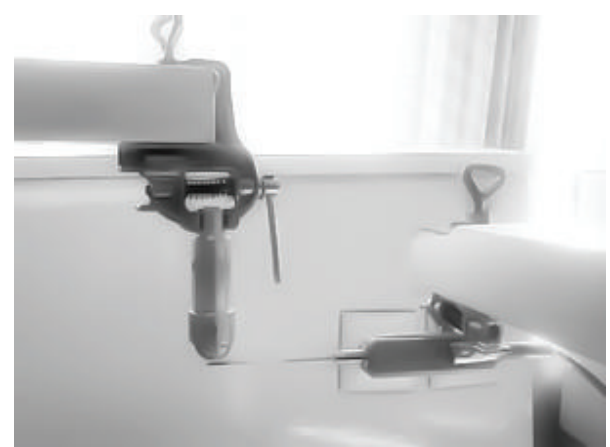

FIGURE 7: Measuring magnetic flux density at $2 \mathrm{~mm}$ from the surface of iron hemisphere.

cannot hold the abrasive power on its surface. Due to centrifugal forces and higher magnetic flux density in corners, much of abrasive powder goes to the corners and lower part of the hemisphere stays bare with almost no abrasive powder. Nevertheless, if the part in front of either hemispherical magnet or iron hemisphere is ferromagnetic, the behavior of circular curves will alter with their distance from the magnet.

2.2. Workpiece. Workpiece is modeled using freeform feature in Solidworks software package. On each specimen, some experiments are performed. Therefore, in order to make a uniform process, path does not have a curvature in the third direction. It should be noted that in the presented model, Figure 10, convex and concave areas possess smooth and high slopes.

For machining this workpiece a 3-axis CNC milling machine is used. $\mathrm{G}$ codes for rough and fine machining are extracted from Powermill software package. Workpiece is made of aluminum 7075. Machining parameters for finishing are kept constant but average surface roughness varies with curvature type. In this study investigation was performed only on the concave area of workpiece. Figure 11 shows measurements performed on this area of the model.

2.3. Condition of Experiment. In order to perform MAF process similar to finish machining, G codes are extracted from Powermill software package. Finishing strategy is used and in strategy remaining thickness is assumed equal to the gap. Rotational speed of the machining head and feed rate are easily set in the software. Moreover, amount of step-over can be set in each step. Step-over is defined as displacement of tool after passing the same path. In experiments step-over is assumed to be $0.1 \mathrm{~mm}$. Other parameters like rotational speed, feed rate, and gap are variables which will be discussed later. It should be noted that by defining thickness of $1 \mathrm{~mm}$ on the path the minimum distance between tool and workpiece surface remains equal to $1 \mathrm{~mm}$. Therefore it is possible that the distance in some areas becomes more. In Figures 12 and 


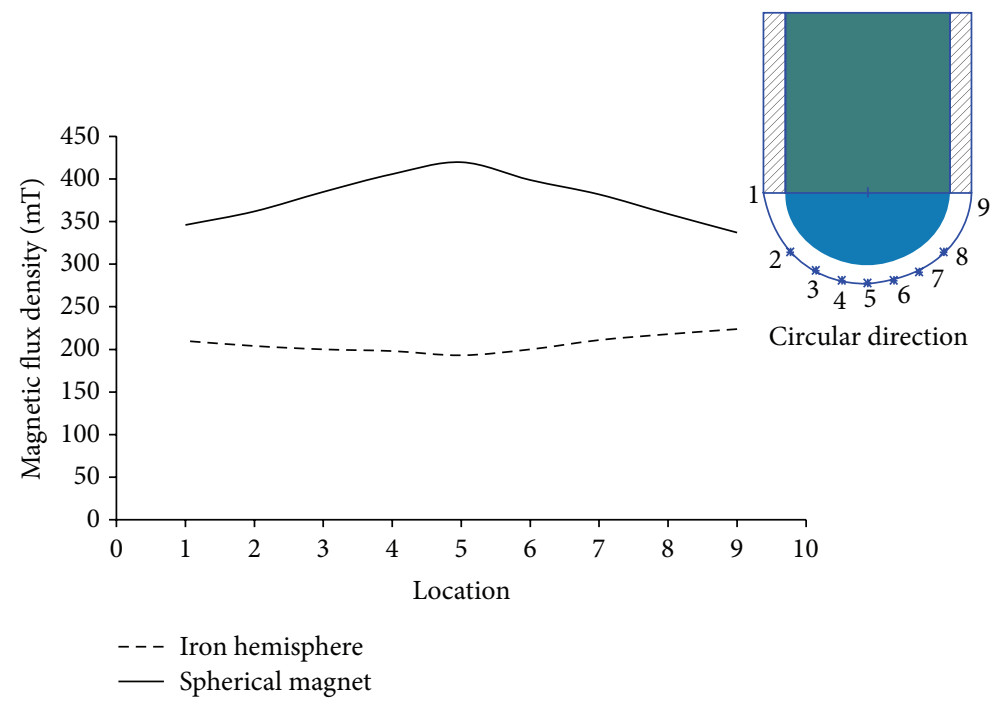

FIGURE 8: Measuring magnetic flux density at $2 \mathrm{~mm}$ from the surface of hemisphere in circular direction.

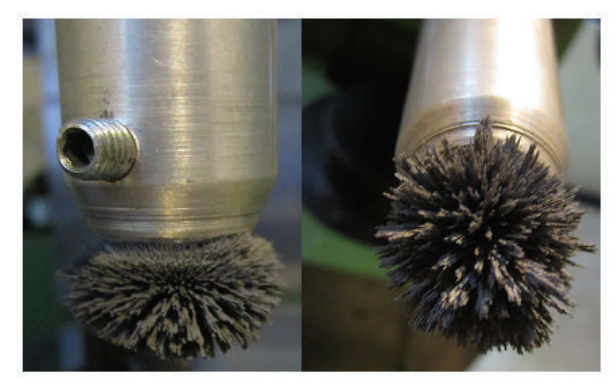

FIGURE 9: Positioning of the magnetic abrasive powder on hemispherical magnet.

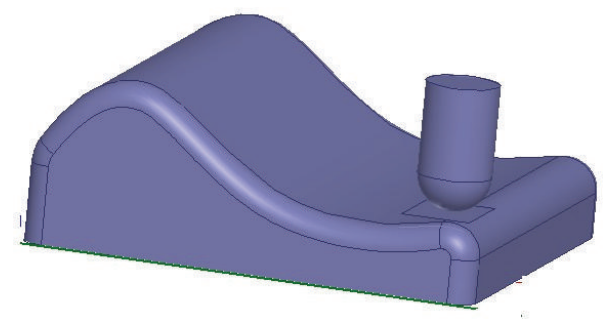

FIGURE 10: Model of workpiece with magnet with hemispherical head.

13, path of the process and the distance which is governed by $G$ codes derived from Powermill software package are illustrated.

The most response of MAF process is the change in average surface roughness of the finished surface and the higher this change, the better and the more effective. Before doing the experimentation, finished surfaces are kept in acetone for 20 minutes. Then Surtronic 3+ surface roughness measuring set with cutoff of 0.8 based on DIN EN IS 0274:1998 is

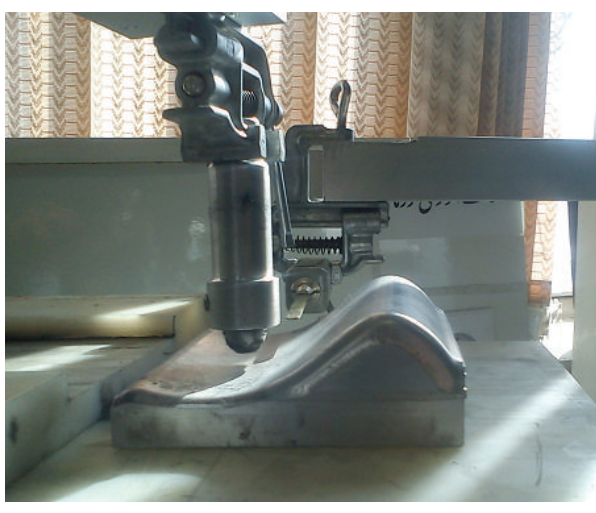

FIGURE 11: Measuring magnetic flux density between magnet and workpiece surface.

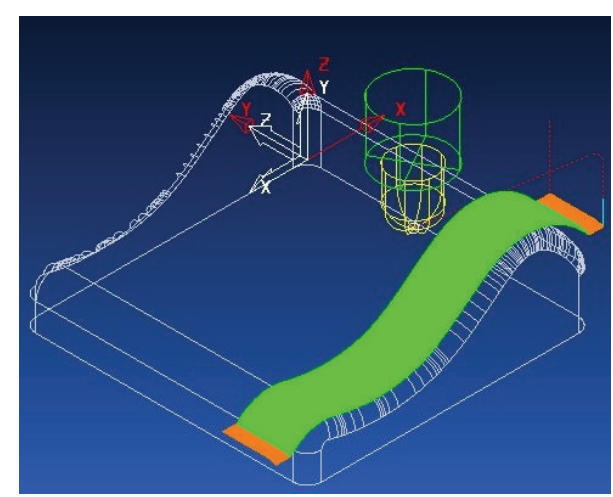

FIGURE 12: Path of finishing process.

applied for measurement [17]. In each area measurements are repeated for some times and average values are considered. It is clear that surface does not have a uniform roughness and different areas yield different roughness values. Figures 


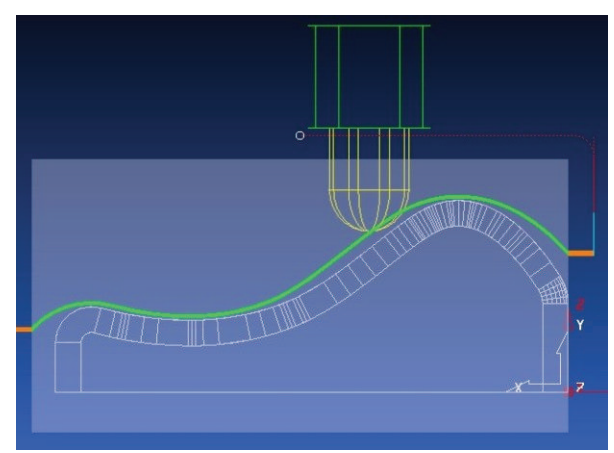

FIGURE 13: Distance between hemispherical head tool and workpiece surface.

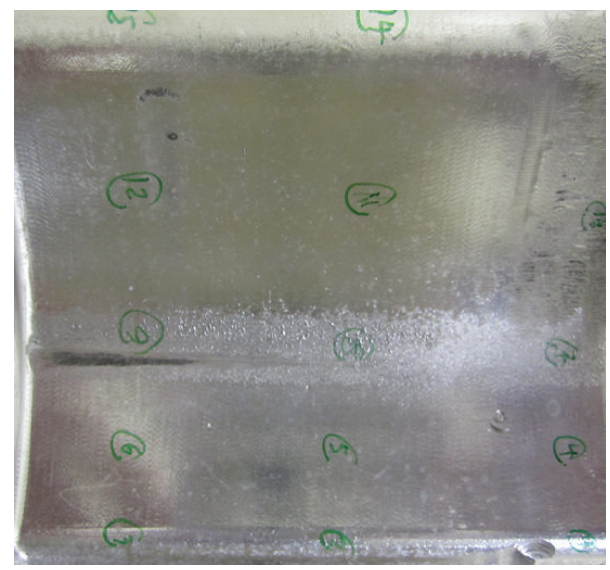

FIGURE 14: Workpiece surface after machining.

14 and 15 show workpiece surface and measuring procedure, respectively. It should be said that during measuring measuring probe should be kept perpendicular to the path and, considering freeform surfaces, the workpiece should be rotated in different directions for making the measurement possible.

To do MAF process unbonded magnetic abrasive powder was used. Iron powder with mesh size of 400\# and alumina abrasive powder with the mesh size of 1200 \# with weight ratio of $3 / 1$ are stirred using a mechanical stirring machine for 20 minutes and become almost homogenous. To make a better connection of the abrasive particles to magnetic ones and avoiding separation in high speeds some amount of SAE30 lubricant is used in the mixture (weight ratio of $5 \%)$. Lubricant acts as a cooling agent and also it reduces frictional forces. Moreover it makes joint between iron and abrasive particles similar to joint between iron particles due to magnetic forces. It should be mentioned that absence of lubricant makes penetration of iron particles into the workpiece surface. Furthermore, rotational movement of the magnet makes abrasive particles separate from magnetic particles in short time. Effect of lack of lubricant usage is illustrated in Figure 16. Regarding distance of $2 \mathrm{~mm}$ from spherical head magnet surface to workpiece surface, the available volume is computed and 2 grams of powder is considered. Experimental constants are listed in Table 2.

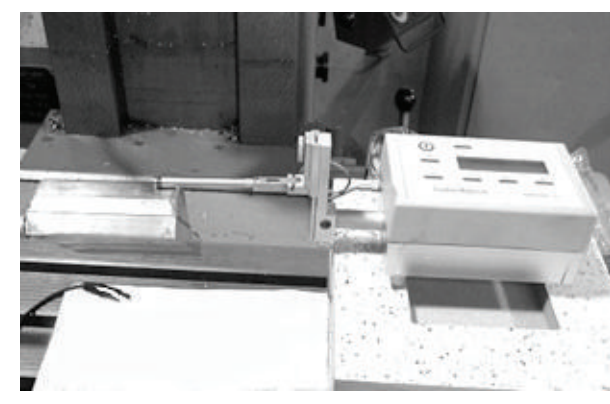

FIGURE 15: Measuring procedure with rotating workpiece.

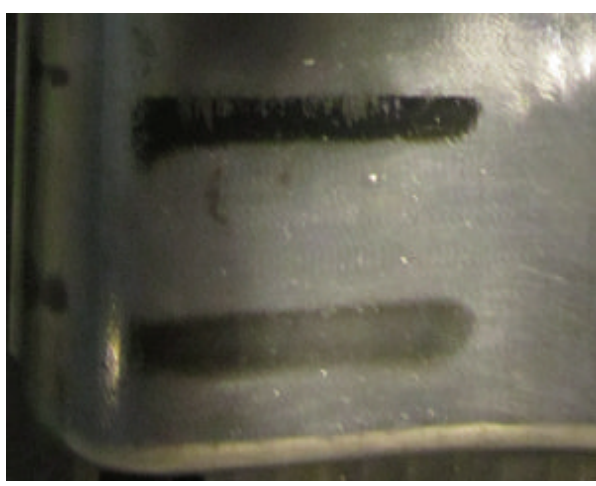

FIGURE 16: Process without applying lubricant.

TABLE 2: Constants in experiments.

\begin{tabular}{lc}
\hline Item & Condition \\
\hline Workpiece & Al alloy \\
Abrasive size & Mesh \#1200 \\
Fe size & Mesh \#400 \\
Abrasive & Al2o3 \\
Weight ratio (magnetic/abrasive) & $3 / 1$ \\
Lubricant & $30 \mathrm{SAE}$ \\
Lubricant ratio in powder & $5 \%$ \\
Permanent magnet & $\mathrm{N} 35$ \\
\hline
\end{tabular}

2.4. Response Surface Method. Suitable design of experiments can decrease the number of experiments. In some conventional methods for design of experiments like factorial design, the number of required experiments increases with the number of parameters. A high number of experiments are both time consuming and expensive. Response surface method is a mathematical-statistical method which is used to model and analyze problems which are affected by bunch of variables [18]. This method also can make a model between inputs and outputs of a problem and reveals it as a mathematical equation. In this method corresponding to the levels and factors constant number of experiments is required. In a complete factorial (general condition) if there are 4 factors varying in 3 levels, total required experiments equal 81. Using response surface method this can decrease to 30 . In these 30 experiments excluding that for central point, no experiment is repetitive. RSM consists of a group of mathematical and 


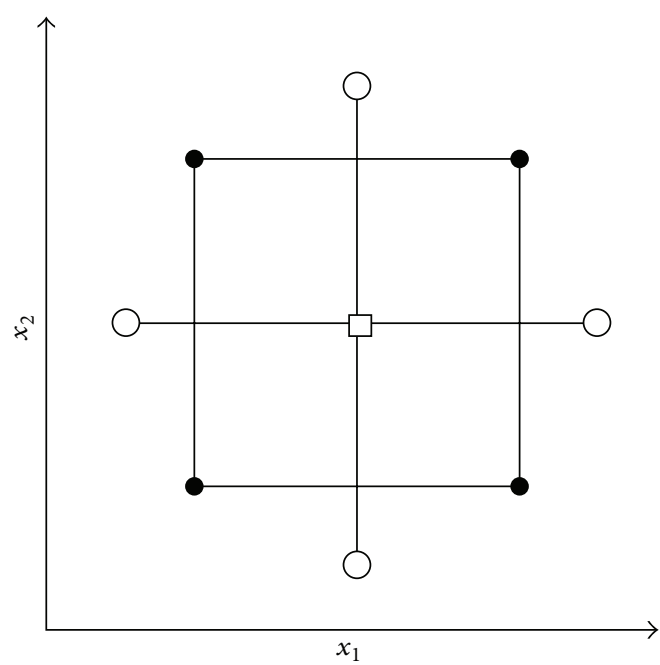

(a)

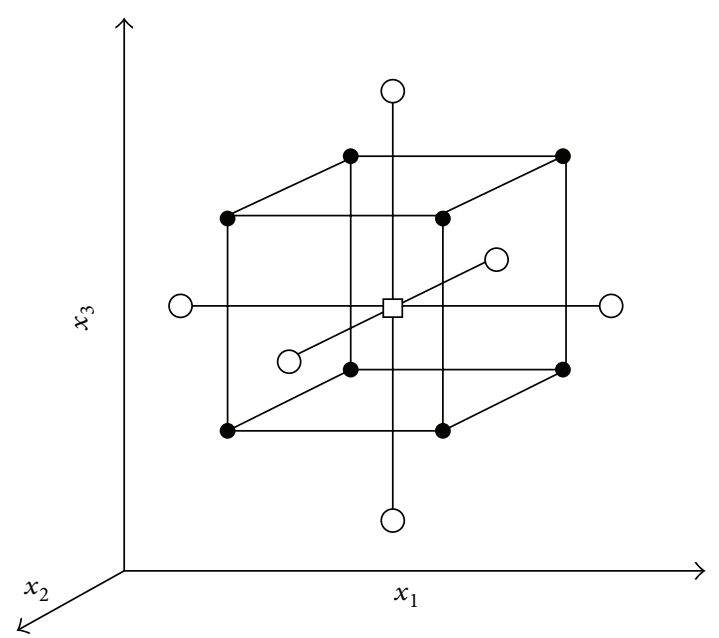

(b)

Figure 17: Central composite designs for optimization: (a) two variables $(\alpha=1.41)$ and (b) three variables $(\alpha=1.68)$; $(\bullet)$ : points of factorial design, (O): axial points, and ( $\square)$ : central point.

statistical techniques that are based on the fit of empirical models to the experimental data obtained in relation to experimental design. Toward this objective, linear or square polynomial functions are employed to describe the system studied and, consequently, to explore (modeling and displacing) experimental conditions until its optimization [19].

Some stages in the application of RSM as an optimization technique are as follows: (1) the selection of independent variables of major effects on the system through screening studies and the delimitation of the experimental region, according to the objective of the study and the experience of the researcher; (2) the choice of the experimental design and carrying out the experiments according to the selected experimental matrix; (3) the mathematic-statistical treatment of the obtained experimental data through the fit of a polynomial function; (4) the evaluation of the model's fitness; (5) the verification of the necessity and possibility of performing a displacement in direction to the optimal region; and (6) obtaining the optimum values for each studied variable.

The simplest model which can be used in RSM is based on a linear function. For its application, it is necessary that the responses obtained are well fitted to the following equation:

$$
y=\beta_{0}+\sum_{i=1}^{k} \beta_{i} x_{i}+\varepsilon,
$$

where $k$ is the number of variables, $\beta_{0}$ is the constant term, $i$ represents the coefficients of the linear parameters, $x_{i}$ represents the variables, and $\varepsilon$ is the residual associated to the experiments. Therefore, the responses should not present any curvature. To evaluate curvature, a second-order model must be used. Two-level factorial designs are used in the estimation of first-order effects, but they fail when additional effects, such as second-order effects, are significant. So, a central point in two-level factorial designs can be used for evaluating curvature. The next level of the polynomial model should contain additional terms, which describe the interaction between the different experimental variables. This way, a model for a second-order interaction presents the following terms:

$$
y=\beta_{0}+\sum_{i=1}^{k} \beta_{i} x_{i}+\sum_{1 \leq i \leq j}^{k} \beta_{i j} x_{i} x_{j}+\varepsilon
$$

where $i j$ represents the coefficients of the interaction parameters. In order to determine a critical point (maximum, minimum, or saddle), it is necessary for the polynomial function to contain quadratic terms according to the equation presented as follows:

$$
y=\beta_{0}+\sum_{i=1}^{k} \beta_{i} x_{i}+\sum_{i=1}^{k} \beta_{i i} x_{i}^{2}+\sum_{1 \leq i \leq j}^{k} \beta_{i j} x_{i} x_{j}+\varepsilon,
$$

where $i$ represents the coefficients of the quadratic parameter. To estimate the parameters in (5), the experimental design has to assure that all studied variables are carried out in at least three factor levels. Thus, two modeling, symmetrical response surface designs are available. Among the more known second-order symmetrical designs are the threelevel factorial design, Box-Behnken design, central composite design, and Doehlert design. These symmetrical designs differ from one another with respect to their selection of experimental points, number of levels for variables, and number of runs and blocks.

In this study central composite design (CCD) is used. This design consists of the following parts: (1) a full factorial or fractional factorial design; (2) an additional design, often a star design in which experimental points are at a distance $\alpha$, from its center; and (3) a central point. Figures 17(a) and 17(b) illustrate the full central composite design for optimization of two and three variables. Full uniformly routable central composite designs present the following characteristics: 


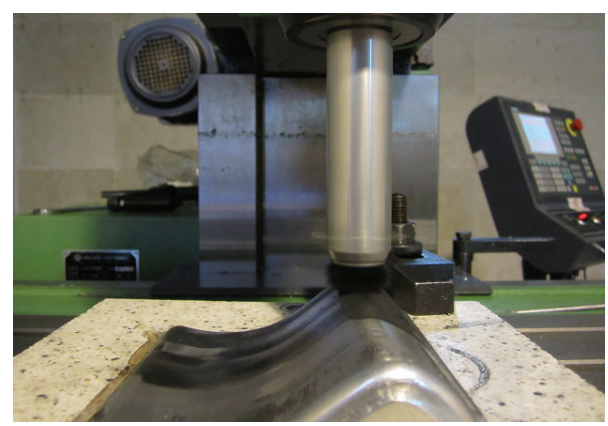

FIGURE 18: Performing MAF process.

(1) They require an experiment number according to $N=$ $k^{2}+2 k+C_{P}$, where $k$ is the factor number and $\left(C_{P}\right)$ is the replicate number of the central point.

(2) $\alpha$-values depend on the number of variables and $P$ value can be calculated by $\alpha=2^{(K-P) / 4}$. But $P$ values less than 0.05 are near to zero. For two, three, and four variables, they are, respectively, 1.41, 1.68, and 2.00.

(3) All factors are studied in five levels $(-\alpha,-1,0,+1,+\alpha)$.

Factorial points which perform the approximation of the interaction terms of the second-order model can be valued in the range of -1 and 1 . Axial points approximate secondorder terms in the second-order regression model. Not only do central points approximate the internal errors but also they contribute to approximation of the second-order terms. The desired response of the design of experiments is the variation percentage of surface roughness which can be computed using

$$
\begin{aligned}
& \Delta \mathrm{Ra}(\%) \\
& =\frac{\text { initial roughness surface }- \text { finish roughness surface }}{\text { initial roughness surface }} \\
& \quad \times 100 .
\end{aligned}
$$

In this paper effect of rotational speed of spindle (cutting speed), feed rate, gap, and amount of powder is investigated. Workpiece is divided into 8 equal sections. In each section, an experiment with its settings is performed. As the path of all experiments is constant, related to step-over and feed rate, time in which each experiment is completed varies. After performing 8 experiments using a ball nose tool, the whole workpiece is machined and measuring is performed again. In each new experiment new and unused powder is applied. MAF is performed on the whole path on the workpiece surface but here only data for concave part is reported. Figure 18 depicts the procedure of MAF on workpiece.

2.4.1. Mathematical Model. First step in usage of response surface method is to find mathematical approximate relations between outputs of the experiments and input variables. In this study experiments are designed based on central composite design. Considered variables are listed in Table 3 in five levels with their values. Mathematical model for the
TABLE 3: Coded values of experiment input factors.

\begin{tabular}{lccccc}
\hline Factors & $-\alpha$ & -1 & 0 & 1 & $\alpha$ \\
\hline Amount of powder, $w(\mathrm{gr})$ & 0.35 & 0.7 & 1.05 & 1.4 & $\mathbf{1 . 7 5}$ \\
Gap, $G(\mathrm{~mm})$ & 0.5 & 1 & 1.5 & 2 & $\mathbf{2 . 5}$ \\
Feed rate, $F(\mathrm{~mm} / \mathrm{min})$ & 10 & 20 & 30 & 40 & $\mathbf{5 0}$ \\
Rotational speed, $V(\mathrm{rpm})$ & 100 & 600 & 1100 & 1600 & $\mathbf{2 1 0 0}$ \\
\hline
\end{tabular}

experiments is formed as a linear second-order regression equation which passes through the points listed in the table or it occupies the closest values to them.

MiniTab v16 is used to analyze the response and also to derive governing mathematical equation. For statistical analysis variance analysis is used.

Considering designed experiments based on response surface method for 4 factors and specifying $\alpha=2$, thirty experiments are required and together with the values of change in percentage of surface roughness are listed in Table 4 . In order to avoid possible errors, experiments were done randomly and not based on order presented in the list.

\section{Data Analysis and Results}

Considering results of surface roughness change, analysis and modification of the model to omit insignificant factors, variance analysis table, and coded governing regression equation's coefficients are presented in Table 5. It should be noticed that those variables are significant in that their $P$ value is less than 0.05 when the reliability is 95 .

Taking into account the outputs from variance analysis and modified model, corresponding explicit equation for the output, based on machining parameters, can be computed using

$$
\begin{aligned}
\Delta \mathrm{Ra}(\%)= & 41.06-3.37 G-3.19 F+2.3533 V \\
& -1.2529 V^{2}-2.23 W \times F-2.03 G \times V \\
& -2.78 F \times V,
\end{aligned}
$$

where model $R$-Sq is $88.63 \%$ and $R$-Sq (adj) is $84.5 \%$ which shows acceptable accuracy of the presented model based on RSM method. Diagrams for scatter of the residuals are presented in Figure 19 which are suitable and matched. Lack of fit of the model becomes insignificant.

3.1. The Effect of Significant Factor. To accurately analyze the effect of parameters, the effect of main parameters and their interactions should be carefully analyzed. In this section the effect of each parameter is discussed. In analysis of the interaction of parameters, other variables are considered at experiment's equilibrium (central point).

3.1.1. The Effect of Gap between the Magnet and Workpiece. Magnetic flux density decreases with distance from the magnet surface. As can be seen in Figure 20, decreasing gap increases the change in surface roughness. The less the distance is, the higher the magnetic force acts on magnetic particles and therefore stiffness of the magnetic abrasive 
TABLE 4: Performed experiments and their values.

\begin{tabular}{|c|c|c|c|c|c|}
\hline Number & Rotational speed, $V$ (rpm) & Feed rate, $F(\mathrm{~mm} / \mathrm{min})$ & Gap, $G(\mathrm{~mm})$ & Amount of powder, $w(\mathrm{~g})$ & $\Delta \mathrm{Ra}(\%)$ \\
\hline 1 & -1 & -1 & -1 & -1 & 35.61 \\
\hline 2 & -1 & -1 & -1 & 1 & 40.59 \\
\hline 3 & -1 & -1 & 1 & -1 & 35.39 \\
\hline 4 & -1 & -1 & 1 & 1 & 37.32 \\
\hline 5 & -1 & 1 & -1 & -1 & 42.11 \\
\hline 6 & -1 & 1 & -1 & 1 & 32.96 \\
\hline 7 & -1 & 1 & 1 & -1 & 37.30 \\
\hline 8 & -1 & 1 & 1 & 1 & 30.87 \\
\hline 9 & 1 & -1 & -1 & -1 & 52.76 \\
\hline 10 & 1 & -1 & -1 & 1 & 57.02 \\
\hline 11 & 1 & -1 & 1 & -1 & 42.19 \\
\hline 12 & 1 & -1 & 1 & 1 & 45.58 \\
\hline 13 & 1 & 1 & -1 & -1 & 43.62 \\
\hline 14 & 1 & 1 & -1 & 1 & 40.50 \\
\hline 15 & 1 & 1 & 1 & -1 & 32.84 \\
\hline 16 & 1 & 1 & 1 & 1 & 30.34 \\
\hline 17 & 0 & 0 & 0 & -2 & 39.46 \\
\hline 18 & 0 & 0 & 0 & 2 & 40.58 \\
\hline 19 & 0 & 0 & -2 & 0 & 45.87 \\
\hline 20 & 0 & 0 & 2 & 0 & 31.99 \\
\hline 21 & 0 & -2 & 0 & 0 & 47.62 \\
\hline 22 & 0 & 2 & 0 & 0 & 37.30 \\
\hline 23 & -2 & 0 & 0 & 0 & 35.11 \\
\hline 24 & 2 & 0 & 0 & 0 & 45.55 \\
\hline 25 & 0 & 0 & 0 & 0 & 40.56 \\
\hline 26 & 0 & 0 & 0 & 0 & 46.06 \\
\hline 27 & 0 & 0 & 0 & 0 & 43.48 \\
\hline 28 & 0 & 0 & 0 & 0 & 41.03 \\
\hline 29 & 0 & 0 & 0 & 0 & 40.27 \\
\hline 30 & 0 & 0 & 0 & 0 & 41.57 \\
\hline 31 & 0 & 0 & 0 & 0 & 38.07 \\
\hline
\end{tabular}

brush increases. On the other hand, with an increase in gap, magnetic force cannot withstand centrifugal forces and therefore much of the powder is thrown away and separated from the magnet surface and process efficiency decreases remarkably. In particular, this case is true for mixed powders in comparison with sintered powder. Considering the type and size of the magnet and amount of magnetic flux, even within the minimum possible distance the imposing force is in order of some tenth or hundredth of micro Newton. Micro forces imposing on abrasive particles make micro chipping occur well and because of the fine size of the particles the penetration depth in workpiece surface is in the order of some tenth or hundredth of microns. Therefore they can easily delete hills and valleys on the surface without producing new ones. Based on previous reports, in MAF on straight surfaces, high reduction in gap introduces roughness on the surface. For curved surfaces, since the selected path can hold the minimum gap of $1 \mathrm{~mm}$, many areas on the spherical surface of the magnet experience higher distances to the workpiece surface and thus in concave areas decreasing gap led to less surface roughness and better finishing.

3.1.2. Effect of Feed Rate. Generally in machining processes the less the feed rate is, the better the surface quality becomes. MAF is not excluded from this general law. High feed rates increase shear force and vibration of the abrasive particles and consequently the quality of the surface decreases. Furthermore, high feed rates change the mechanism of deformation and separation of the abrasive particles and increase surface roughness. Moreover, in lower feed rates abrasive powder in the contact interface with workpiece surface has more time for finishing. It should be noted that lowering feed rate increases machining time and production costs. Figure 21 depicts the influence of feed rate.

3.1.3. Effect of Cutting Speed. Regression coefficient of rotational speed almost equals that of feed rate with this difference that higher values of cutting speed positively affect surface 

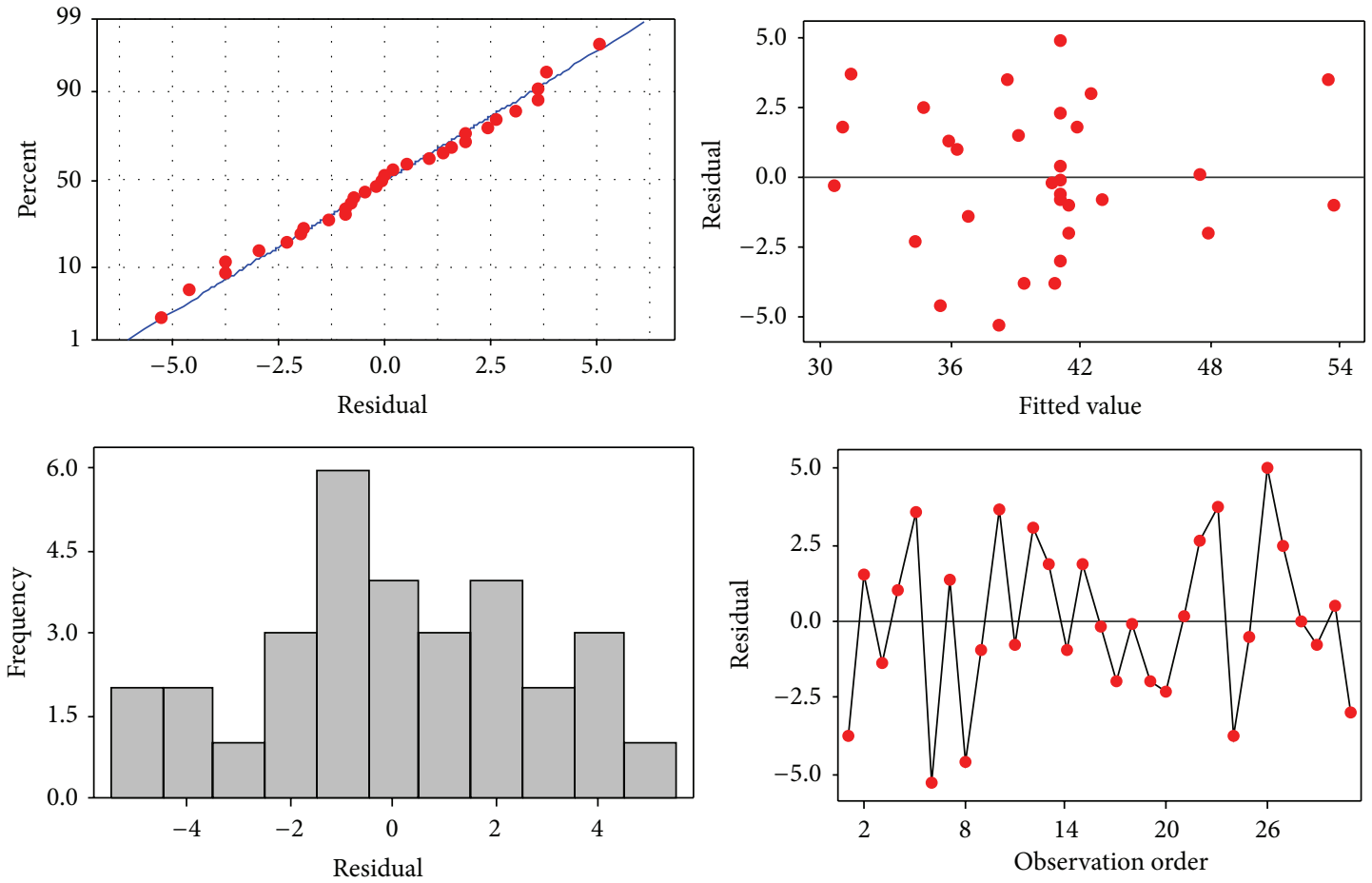

FIGURE 19: Diagrams for residual distribution.

TABLE 5: Regression model coefficients and lack of fit in primary and modified models.

\begin{tabular}{|c|c|c|c|c|}
\hline \multicolumn{2}{|c|}{ Modified model } & \multicolumn{2}{|c|}{ Initial model } & \multirow{2}{*}{ Terms } \\
\hline Coefficient regression & $P$ value & Coefficient regression & $P$ value & \\
\hline 41.06 & 0.000 & 41.57 & 0.000 & Constant \\
\hline-0.18 & 0.709 & -0.18 & 0.725 & $w$ \\
\hline-3.37 & 0.000 & -3.37 & 0.000 & $G$ \\
\hline-3.19 & 0.000 & -3.19 & 0.000 & $F$ \\
\hline 2.35 & 0.000 & 2.35 & 0.000 & $V$ \\
\hline - & - & -0.31 & 0.512 & $w \times w$ \\
\hline - & - & -0.58 & 0.229 & $G \times G$ \\
\hline - & - & 0.29 & 0.53 & $F \times F$ \\
\hline-1.25 & 0.004 & -1.30 & 0.013 & $V \times V$ \\
\hline - & - & -0.03 & 0.95 & $G \times w$ \\
\hline-2.23 & 0.001 & -2.23 & 0.003 & $F \times w$ \\
\hline- & - & 0.66 & 0.30 & $V \times w$ \\
\hline - & - & -0.14 & 0.81 & $F \times G$ \\
\hline-2.03 & 0.002 & -2.03 & 0.005 & $V \times G$ \\
\hline-2.78 & 0.000 & -2.78 & 0.000 & $V \times F$ \\
\hline- & 0.655 & - & 0.553 & Lack of fit \\
\hline
\end{tabular}

quality. Due to changes in material plastic behavior in higher cutting speeds, shear forces decrease and consequently surface quality increases. Figure 22 shows the effect of cutting speed (rotational speed of machining head).

As can be seen with increasing cutting speed to $1600 \mathrm{rpm}$, the change in surface roughness increases but higher increase in cutting speed decreases surface quality. In high cutting speeds centrifugal forces surpass magnetic forces and abrasive particles are thrown away. Reduced amount of powder causes higher surface roughness. It should be noted that interaction of rotational speed and gap and also rotational speed and feed rate are also significant on the process. Figures 23 and 24 are the result of analysis of experiments showing the effect of interaction between factors. It can be seen from Figure 23 that with a low feed rate increasing cutting speed reduces surface roughness and aforementioned limit for increasing rotational speed does not exist. Figure 24 shows that in the minimum gap suitable results can be achieved. 


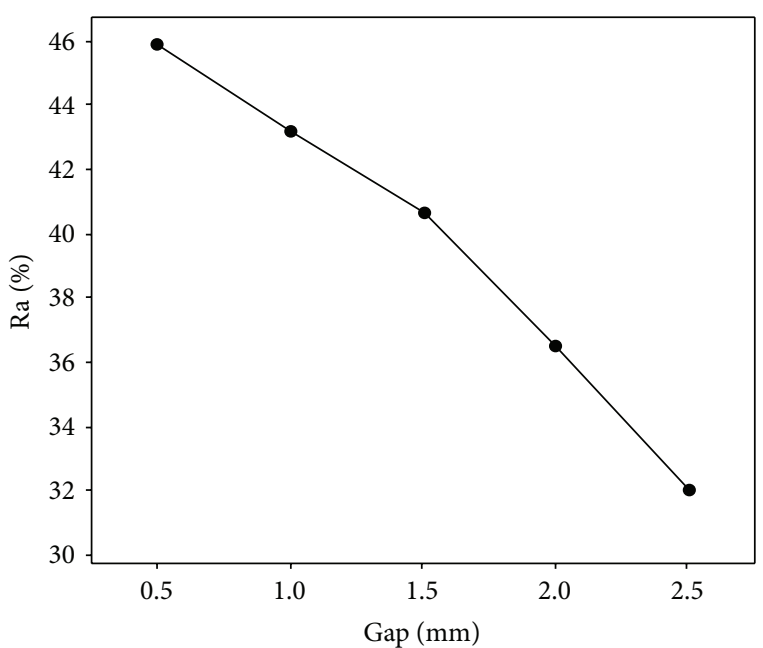

FIGURE 20: The effect of magnet-workpiece gap.

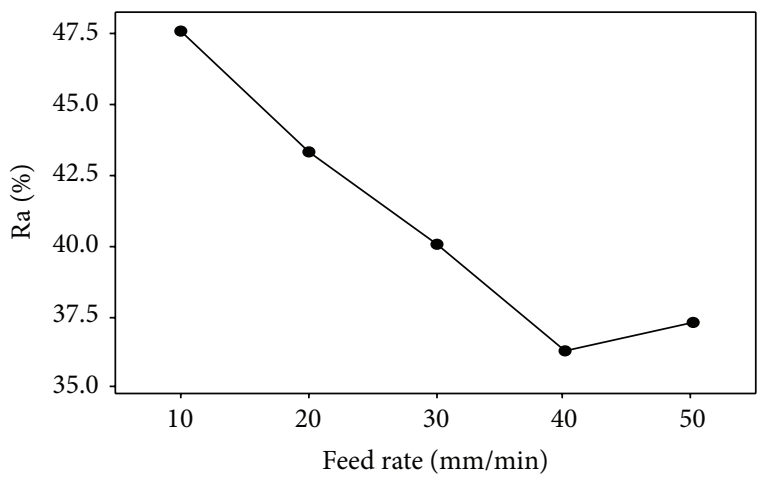

FiguRE 21: The effect of feed rate.

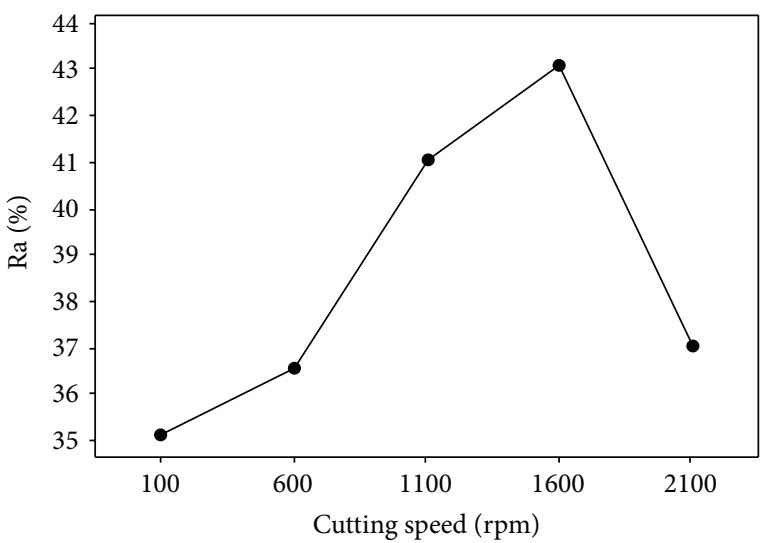

Figure 22: The effect of cutting speed.

3.1.4. Effect of Powder Amount. Considering variance analysis and Figure 25, this factor is not effective on the process and increasing powder amount does not affect surface roughness. However, the magnet in the defined gap can carry only limited amount of powder. Otherwise, due to sticking character of the combined magnetic abrasive powder caused by the

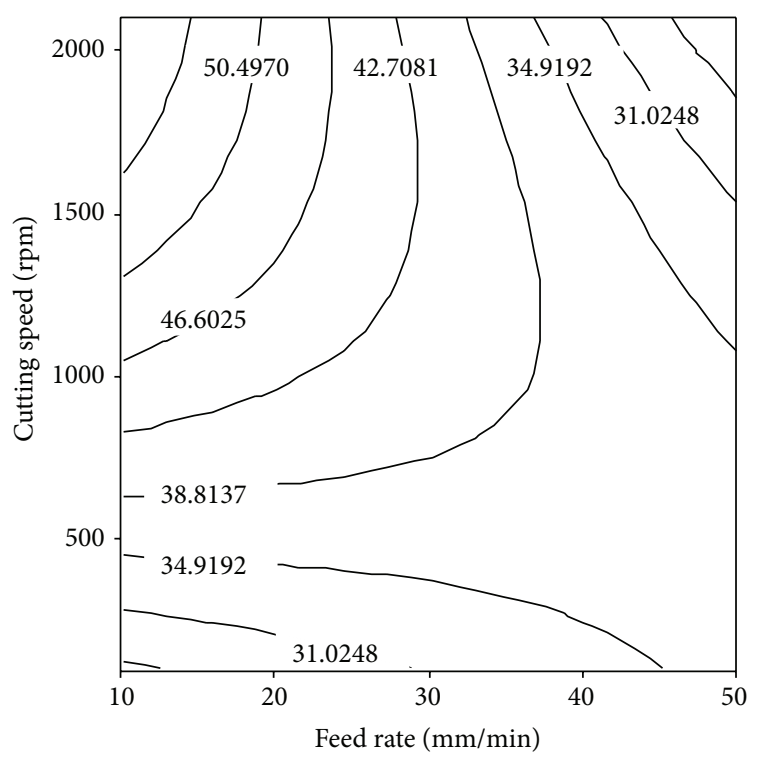

FigurE 23: Interaction effect of cutting speed and feed rate.

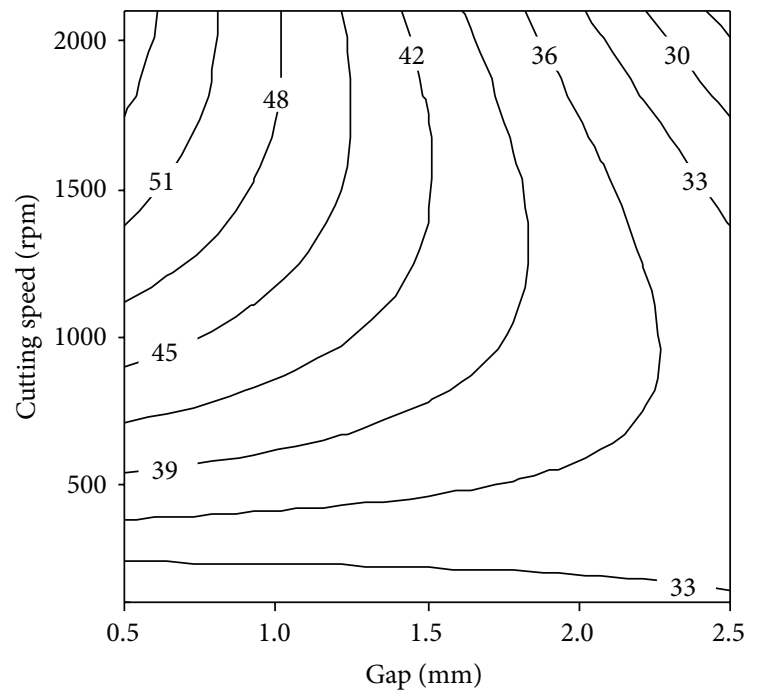

FIGURE 24: Interaction effect of cutting speed and gap.

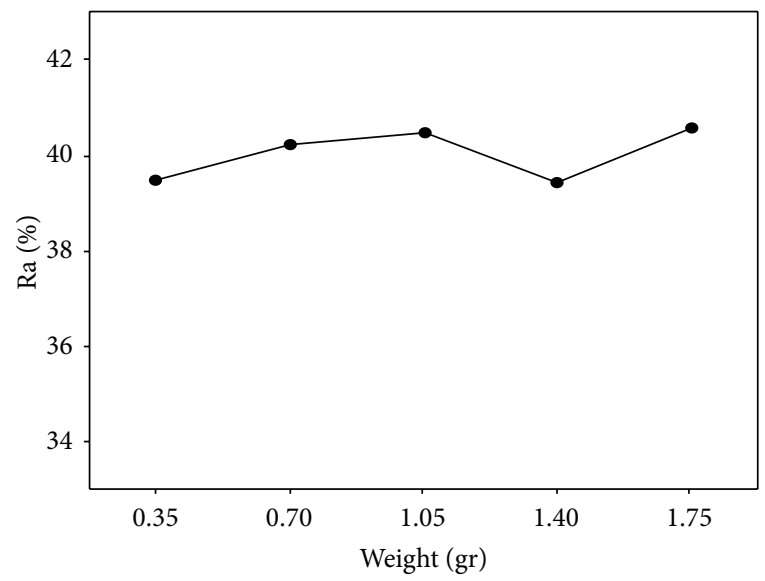

Figure 25: Effect of amount of powder. 
TABLE 6: Optimum results.

\begin{tabular}{lccccc}
\hline Optimization & Cutting speed & Feed rate & Gap & Amount of powder & $\Delta$ Ra $(\%)$ \\
\hline Simulation & 2100 & 10 & 0.5 & 1.75 & $\% 75.2$ \\
Experiment & 2100 & 10 & 0.5 & 1.75 & $\% 62.1$ \\
\hline
\end{tabular}

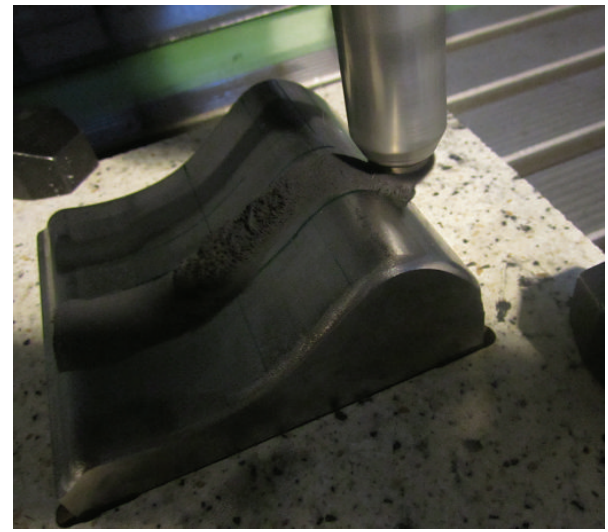

FIGURE 26: Remaining powder on the workpiece surface.

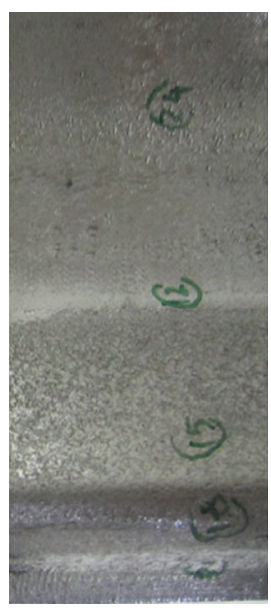

(a)

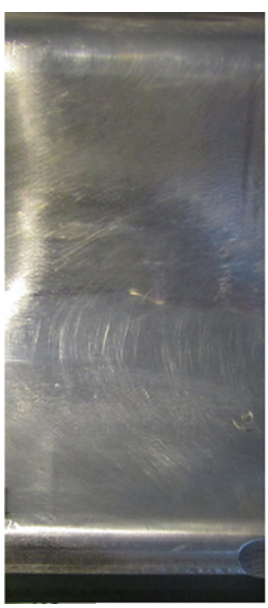

(b)
FIgURE 27: Workpiece surface (a) before MAF and (b) after MAF.

lubricant, part of it will remain on the surface. Figure 26 shows this phenomenon.

\subsection{Finding Optimum Condition for MAF Operation. Con-} sidering results from analysis of diagrams and governing mathematical model, software suggests an optimum solution and predicts the change in surface roughness. It can be seen that results taken from analysis of the experiments are confirmed with high accuracy and change in surface roughness can be achieved up to $65 \%$. These results are presented in Table 6 . Figure 27 shows process effect on the workpiece surface.

\section{Conclusion}

In this study in addition to simulation and measuring the magnetic flux density of iron hemisphere and hemispherical magnet, appropriate tool was manufactured for MAF process. Due to better distribution and availability of magnetic flux density on hemispherical magnet surface, it is used as MAF tool. The behavior of hemispherical magnet passing concave surfaces and its magnetic flux density is also investigated. The discrepancy between simulated and measured magnetic flux density varies between $15 \%$ and $26 \%$. Simulation overestimates magnetic flux density. Average magnetic flux density imposing on aluminum workpiece surface in $2 \mathrm{~mm}$ distance from the magnet surface is 0.36 Tesla.

Based on results, gap possesses the highest influence on the change of surface roughness. In lower gaps this change is higher.

According to regression coefficients the effects of feed rate and cutting speed are equal. However, lower feed rate and higher cutting speed produce better results. Based on the interaction effect of cutting speed and feed rate and also cutting speed and gap, the limitation in increasing cutting speed is vanished because with decreasing gap and feed rate high cutting speed can be selected for the process. Powder amount has a negligible effect on the process even though higher amount of powder has a slightly positive influence. The suggested regression model correlates well with the experiment outputs. Optimum parameters are gap size of $0.5 \mathrm{~mm}$, feed rate of $10 \mathrm{~mm} / \mathrm{min}$, rotational speed of $2100 \mathrm{rpm}$, and powder amount of $1.75 \mathrm{gr}$. This condition can improve surface roughness up to $75 \%$ based on simulation results. In performed experiments, based on the ranges of the variables, improvement was reported up to $62 \%$. Difference was $13 \%$ percent, which is acceptable.

On concave surfaces, surface roughness value changes from $1.3 \mu \mathrm{m}$ to $0.2 \mu \mathrm{m}$ and in some points measurements show surface roughness of $.08 \mu \mathrm{m}$.

\section{Competing Interests}

The authors declare that they have no competing interests.

\section{References}

[1] V. K. Jain, "Magnetic field assisted abrasive based micro-/nanofinishing," Journal of Materials Processing Technology, vol. 209, no. 20, pp. 6022-6038, 2009.

[2] S. M. Ji, Y. M. Xu, G. D. Chen, and M. S. Jin, "Comparative study of magnetic abrasive finishing in free-form surface based on different polishing head," Materials Science Forum, vol. 675, pp. 593-596, 2011. 
[3] S. Jha and V. K. Jain, "Nanofinishing techniques," in Micromanufacturing and Nanotechnology, N. P. Mahalik, Ed., pp. 171-195, Springer, Berlin, Germany, 2006.

[4] D. K. Singh, V. K. Jain, and V. Raghuram, "Parametric study of magnetic abrasive finishing process," Journal of Materials Processing Technology, vol. 149, no. 1-3, pp. 22-29, 2004.

[5] B. Girma, S. S. Joshi, M. V. G. S. Raghuram, and R. Balasubramaniam, "An experimental analysis of magnetic abrasives finishing of plane surfaces," Machining Science and Technology, vol. 10, no. 3, pp. 323-340, 2006.

[6] B.-H. Yan, G.-W. Chang, J.-H. Chang, and R.-T. Hsu, "Improving electrical discharge machined surfaces using magnetic abrasive finishing," Machining Science and Technology, vol. 8, no. 1, pp. 103-118, 2004.

[7] R. S. Mulik and P. M. Pandey, "Magnetic abrasive finishing of hardened AISI 52100 steel," The International Journal of Advanced Manufacturing Technology, vol. 55, no. 5-8, pp. 501515, 2011.

[8] C.-T. Lin, L.-D. Yang, and H.-M. Chow, "Study of magnetic abrasive finishing in free-form surface operations using the Taguchi method," The International Journal of Advanced Manufacturing Technology, vol. 34, no. 1-2, pp. 122-130, 2007.

[9] S. Yin and T. Shinmura, "A comparative study: polishing characteristics and its mechanisms of three vibration modes in vibration-assisted magnetic abrasive polishing," International Journal of Machine Tools and Manufacture, vol. 44, no. 4, pp. 383-390, 2004.

[10] M. D. Zhang, M. Lv, and H. L. Chen, "Theoretical research on polishing free-form surface with magnetic abrasive finishing," Key Engineering Materials, vol. 392-394, pp. 404-408, 2009.

[11] Y. H. Ding, X. G. Yao, X. X. Wang, and S. C. Yang, "Study on the performances of the ferromagnetic poles based on the curved surface magnetic abrasive finishing," Key Engineering Materials, vol. 359-360, pp. 365-368, 2008.

[12] M. Anzai, T. Yoshida, and T. Nakagawa, "Magnetic abrasive automatic polishing of curved surface, focused on experimental equipments and characterization," RIKEN Review, no. 12, pp. 15-16, 1996.

[13] L.-D. Yang, C.-T. Lin, and H.-M. Chow, "Optimization in MAF operations using Taguchi parameter design for AISI304 stainless steel," The International Journal of Advanced Manufacturing Technology, vol. 42, no. 5-6, pp. 595-605, 2009.

[14] D. K. Singh, V. K. Jain, and V. Raghuram, "Experimental investigations into forces acting during a magnetic abrasive finishing process," The International Journal of Advanced Manufacturing Technology, vol. 30, no. 7-8, pp. 652-662, 2006.

[15] N. K. M. Naif, "Study on the parameter optimization inmagnetic abrasive polishing forbrass cuzn33plate using Taguchi method," The Iraqi Journal for Mechanical and Material Engineering, vol. 12, no. 3, pp. 596-615, 2012.

[16] R. S. Gill, "Effect of the process parameters on the surface roughness during magnetic abrasive finishing process on ferromagnetic stainless steel workpieces," International Journal of Mechanical Engineering and Technology, vol. 4, pp. 310-316, 2013.

[17] http://www.taylor-hobson.com/.

[18] D. C. Montgomery, Design and Analysis of Experiments, John Wiley \& Sons, 2008.

[19] M. A. Bezerra, R. E. Santelli, E. P. Oliveira, L. S. Villar, and L. A. Escaleira, "Response surface methodology (RSM) as a tool for optimization in analytical chemistry," Talanta, vol. 76, no. 5, pp. 965-977, 2008. 

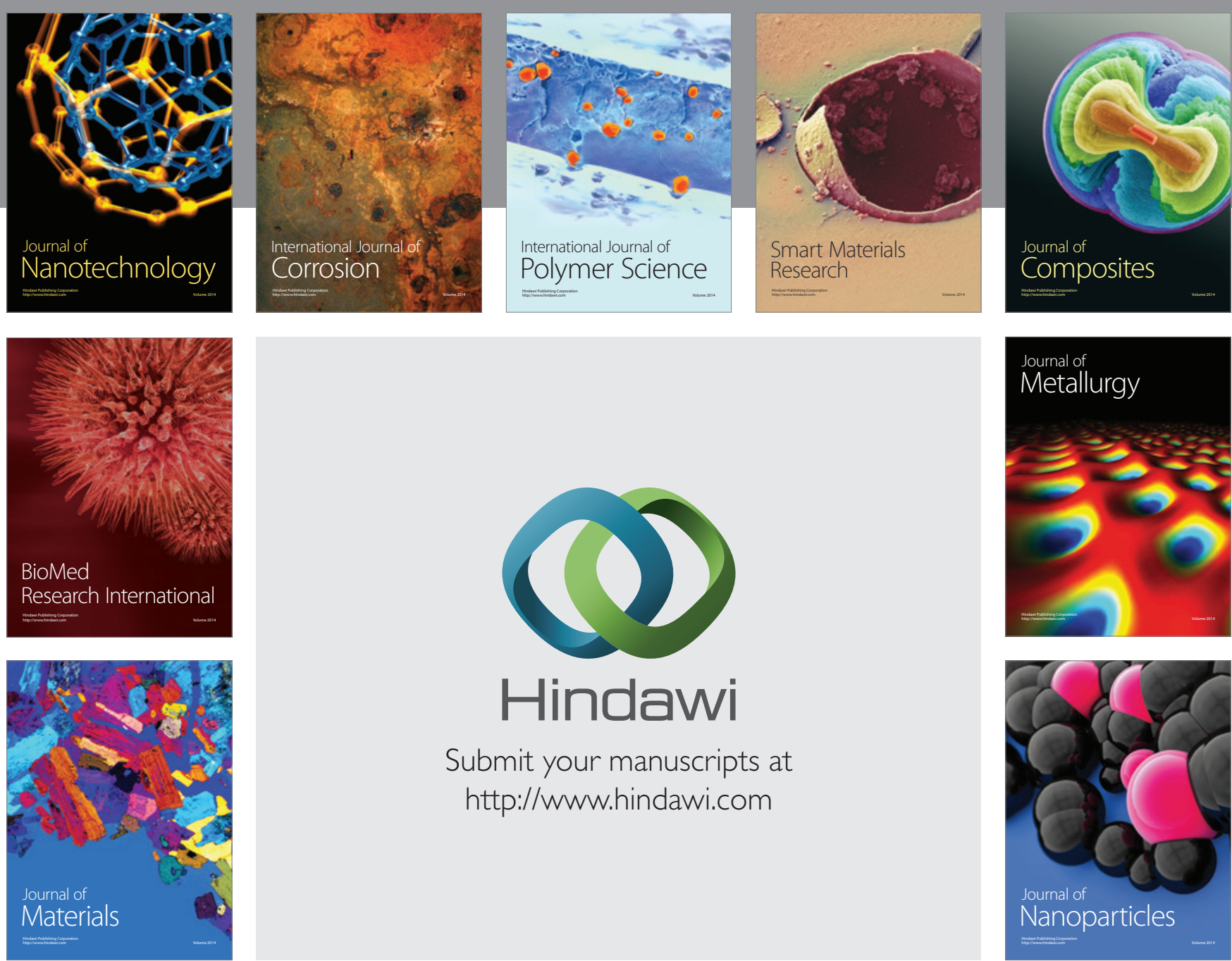

\section{Hindawi}

Submit your manuscripts at

http://www.hindawi.com

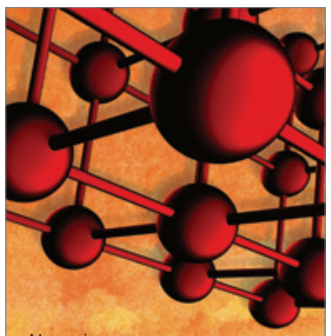

Materials Science and Engineering
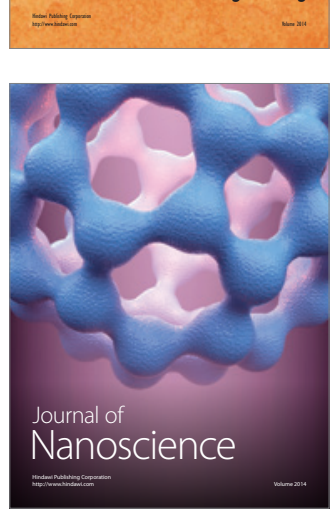
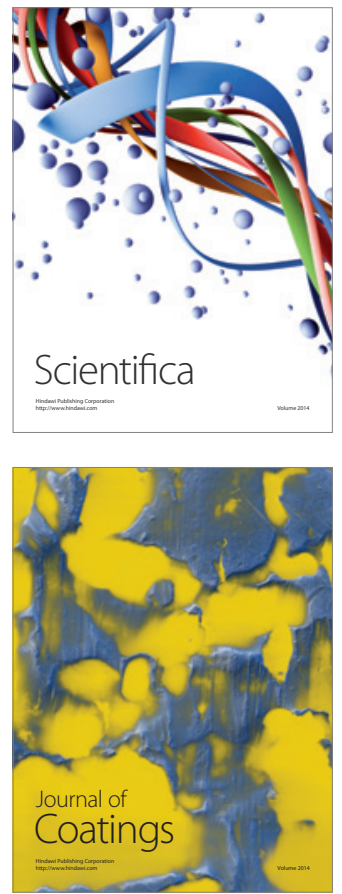
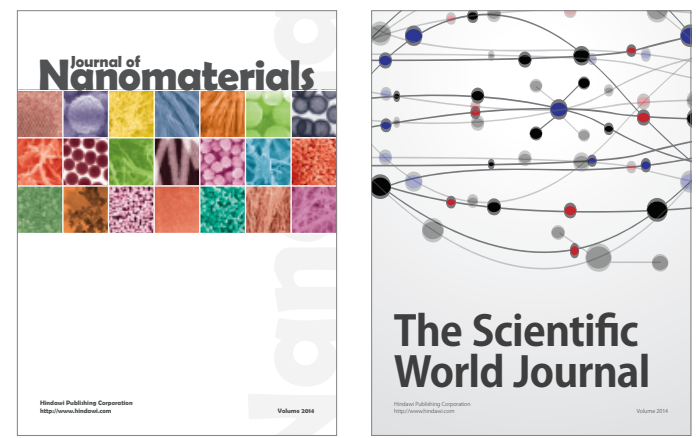

The Scientific World Journal
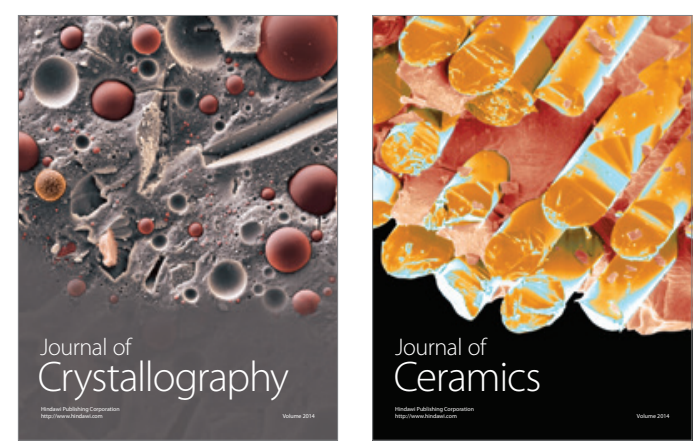
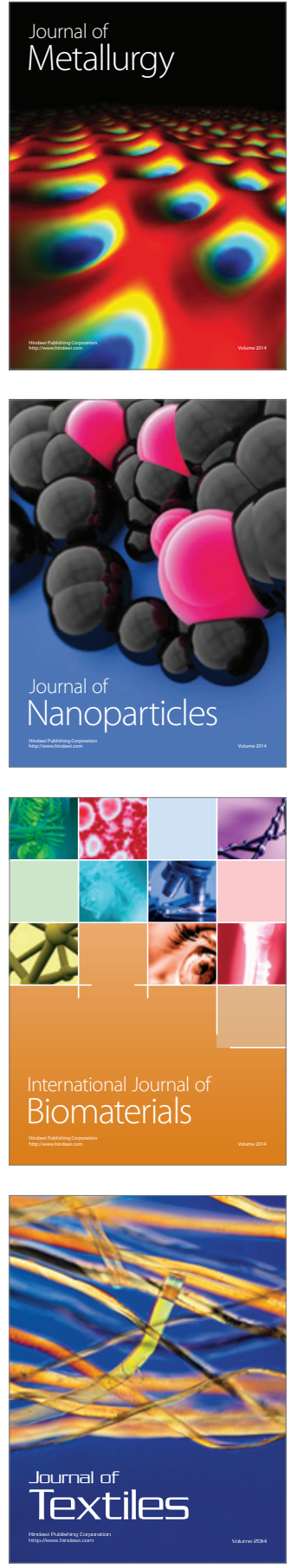